\title{
LISBOA, CIUDAD ONÍRICA EN RÉQUIEM, DE ANTONIO TABUCCHI
}

\author{
Lisbon, Oneiric City in Antonio Tabucchi’s Requiem
}

\section{RESUMEN}

El escritor Antonio Tabucchi homenajea a Portugal en Réquiem. Una alucinación, nouvelle que resignifica Lisboa mediante la polisensorialidad y el estado onírico. La ciudad se reconstruye y se torna de vital importancia para el protagonista, quien emprende un viaje personal e íntimo con el fin de llenar vacíos de su vida lúcida, fragmentos que, al igual que los distintos lugares de la ciudad que atraviesa, están dispersos y reflejan la vida posmoderna tantas veces problematizada por el autor en su obra.

Para examinar la reconstrucción del espacio que plantea la obra del escritor italiano, recurriremos a algunas hipótesis de la Topofilia, la Geocrítica y la Antropología Urbana desarrolladas por Tuan, Westphal y García Canclini, respectivamente. El objetivo final es evaluar cómo la descripción de la ciudad es el punto de partida para reflexionar, en Réquiem..., acerca de cuestiones como el paso del tiempo, la vida y la muerte.

\section{UNIVERSUM}

\section{MAIRA SCORDAMAGLIA}

Centro de Estudios de Literatura Comparada "M. T. Maiorana", Facultad de Filosofía y Letras, Universidad Católica Argentina, Argentina.

Correo electrónico:

maira.scordamaglia@gmail.com

ORCID: 0000-0003-4634-0505

ResearchGate:

Scholar.google:

Academia.edu: MairaScordamaglia

Palabras claves: Tabucchi, Réquiem, Topofilia, polisensorialidad. 


\begin{abstract}
Antonio Tabucchi's nouvelle Requiem: A Hallucination is a tribute to Portugal in which Tabucchi resignifies Lisbon by enhancing polisensoriality and an oneiric state. The city is reconstructed and becomes of vital importance for the protagonist, who undertakes an intimate journey in order to fill the gaps of his life, scattered and fragmented as the portrayal of the places he visits. All of them convey the postmodern way of life often problematized by the author in his works.

In order to examine the reconstruction of space carried out by the Italian author's nouvelle, we will recur to some hypotheses from Tuan's Topophilia, Westphal's Geocriticism and García Canclini's Urban Anthropology. The final aim is to evaluate how the description of the city in Requiem... becomes the start point to reflect on issues such as the passing of time, life and death.
\end{abstract}

Keywords: Tabucchi, Requiem, Topophilia, polisensoriality.

\title{
UN PERSONAJE EN BUSCA DE UN ESCRITOR
}

En su nouvelle Réquiem. Una alucinación (1991), el escritor italiano Antonio Tabucchi ${ }^{1}$ dedica un homenaje a un país por él amado, Portugal. En este texto, escrito íntegramente en portugués, el innominado narradorprotagonista vuelve a Lisboa, no físicamente, sino en un estado de ensoñación. En su recorrido onírico se halla en lugares icónicos de la ciudad y se encuentra con los fantasmas de seres queridos que dan sentido a su alucinación. Nos interesa enfocarnos en los espacios transitados, extremadamente significativos

1 Antonio Tabucchi (Pisa, 1943 - Lisboa, 2012). Entusiasta lector desde pequeño, se abocó a las letras en su juventud. Conoció, durante un viaje en tren, Tabaquería, de Fernando Pessoa, y se convirtió en un ferviente lector de la obra del poeta portugués, y en un gran difusor de la literatura y cultura portuguesas en Italia. La obra narrativa de Tabucchi, iniciada con la publicación de Piazza d'Italia en 1975, plantea la ficción como vía de escape de una realidad monótona y angustiante. Sus personajes y los conflictos que atraviesan reflejan las dificultades que conlleva la búsqueda de la propia identidad; de ahí que el viaje (real, inerior u onírico) y la búsqueda de sí mismo sean constantes en la mayoría de sus obras. La reivindicación de lo periférico, la problematización de la complejidad de su tiempo, la búsqueda de un futuro a través del retorno nostálgico a la memoria y al pasado, la conciencia de la fragmentación de la vida y un optimismo subyacente, a pesar de los límites y las dificultades, convierten a Tabucchi en un "humanista posmoderno" (Capano, 2007). 
en la novela, pues, si bien es fácil identificar las calles, monumentos, edificios y barrios $^{2}$ mencionados por Tabucchi, desconfiamos de la apariencia de inocente repertorio de atractivos turísticos que la novela simula ser. Por el contrario, intentaremos estudiar cómo la ciudad portuguesa se resignifica en este texto a través de la experiencia individual del protagonista, teniendo en cuenta que no hay dos personas que perciban "de forma precisamente igual" la misma realidad (Tuan, 2007: 15).

El narrador de la nouvelle se sitúa bajo un árbol en una finca portuguesa y mientras lee el Libro del desasosiego, de Fernando Pessoa, se adormece. Es así como ingresa en el sueño donde se dará su viaje por la capital lusa, cuya resignificación se sustenta, en primer lugar, por el estado onírico. Dado que en los sueños se despliega lo más profundo e íntimo del ser mediante asociaciones impensables en la vigilia, podemos considerar que este encuentro con Lisboa es especialmente personal para el protagonista.

En segundo lugar, es preciso señalar que la resignificación se realiza por medio de la percepción del narrador. El espacio existe porque es percibido por un sujeto (Westphal, 2015: 53). Para examinar el modo en que la obra de Tabucchi reconfigura Lisboa, recurriremos a algunas propuestas de la Topofilia de Yi-Fu Tuan, la Geocrítica desarrollada por Bertrand Westphal y los análisis de Antropología Urbana de Néstor García Canclini. La hipótesis que guía este trabajo es que la Lisboa de Réquiem es un espacio evocado y reinventado a partir de los conflictos existenciales del personaje que la percibe.

En su recorrido onírico, el protagonista de la nouvelle tiene el objetivo de encontrarse con el fantasma de Fernando Pessoa. Pero hasta dar con él transcurre un tórrido día estival en el cual habita una ciudad casi vacía y aprovecha su estadía para hablar con los fantasmas de viejos allegados (como

2 Suscribimos a la distinción explicada por Tudoras entre las nociones de lugar y espacio. Mientras el primer término refiere a una serie de elementos que coexisten y que pueden describirse desde un punto de vista estático, el espacio es la puesta en común de dichos elementos a través del desplazamiento de un objeto móvil. De esta manera, los lugares, que poseen un carácter "geométrico" adquieren una dimensión "antropológico-existencial" (2006: 133). 
su amigo Tadeus y su propio padre) y con lisboetas desconocidos. Si bien la unidad temporal delimita la trama — pues la acción transcurre en un lapso de doce horas - , la dimensión espacial se expresa de manera fragmentaria, como si el protagonista saltara de un lugar al otro de manera arbitraria, algo muy similar a lo que nos ocurre durante los sueños. Es relevante señalar que el narrador rehace el itinerario de viajes previos, y sabe qué lugares debe volver a visitar y qué calles tomar para llegar a ellos: esto es significativo porque nunca se visita dos veces la misma ciudad, y tampoco se es el mismo al retornar de ella; el espacio cambia, y las percepciones en torno a él también lo hacen. Lisboa no será la misma que era antes para el personaje, y él tampoco será el mismo después de este nuevo viaje.

\section{LA APROXIMACIÓN TOPOFÍLICA: PERCEPCIÓN Y ACTITUD}

Tabucchi hace que en este viaje por Lisboa el protagonista se valga de sus cinco sentidos para registrar la ciudad. Como señala Tuan, "percibir es una actividad, es aprehender el mundo" (2007: 24). En efecto, el narrador realiza este trabajo de aprehensión y, al hacerlo, reconstruye su propia Lisboa, que se recrea mediante sus sabores, sus olores, la temperatura de su día, sus voces y su música, que le confieren una cierta "tridimensionalidad", vividez o realidad a este sueño y, por extensión, a la novela.

El geógrafo chino-estadounidense distingue tres ejes involucrados en la construcción del lazo afectivo que se puede desarrollar con un determinado espacio. Estos son la percepción, la actitud y la cosmovisión. El primer eje pone en juego la respuesta de los sentidos frente a los estímulos, teniendo en cuenta que lo que percibimos y retenemos es aquello que tiene un valor para nosotros. La actitud enfatiza la perspectiva cultural que se da entre el espacio y el individuo, la cual se logra mediante la experiencia, y la cosmovisión, en palabras del autor, "es la experiencia conceptualizada" socialmente, ya que supone creencias y actitudes compartidas por un conjunto de personas (Tuan, 2007: 13). Es imposible que estos tres ejes que atraviesan la consideración de los referentes espaciales en la novela no estén afectados por el factor del 
tiempo, el cual secuencia, posibilita y delimita toda experiencia humana.

Para analizar cómo Tabucchi entreteje sensorialidad y espacio, ofreceremos un recorrido por los lugares de Lisboa en los que acaecen los hitos más relevantes de la novela. Al inicio, el narrador se encuentra vacacionando en una finca, pero al quedarse dormido, en su sueño toma conciencia de que se halla en el Muelle de Alcântara, situado en la desembocadura del Tajo, que es el punto de entrada y de salida del sueño. El límite entre el medio acuoso y el terrestre marcará cada ingreso o egreso a un estadio nuevo. Al finalizar el viaje por su Lisboa onírica, el personaje volverá al muelle para despertar y hallarse de nuevo bajo la morera en el Azeitâo, confiriéndole a este estado alucinatorio un sentido circular, cerrado y perfecto.

Dado que el encuentro con Pessoa sería a la medianoche, el narrador, que entra al sueño en pleno mediodía, recorrerá distintos puntos de Lisboa para toparse con otros personajes y fantasmas de su memoria. Tras perderse en un taxi en las calles de la ciudad siente un acaloramiento extremo, manifestado por medio de la sudoración. Aquí aparece el sentido del tacto. El protagonista nota su sudor y reflexiona: "debe ser el calor, el calor y un ataque de ansiedad, algunas veces la ansiedad me hace sudar" (Tabucchi, 1991: 21). Al indagar sobre el sentido háptico, Tuan explica que este confiere una experiencia directa con la realidad: el niño, en sus primeros años de vida, aprehende el mundo tocándolo, estando cerca del suelo, sintiendo la resistencia física del mundo contra su piel. Así, el narrador muestra cómo siente que él no solamente sueña con Lisboa, sino que está en ella, experimentando las altas temperaturas del mediodía en verano. El sudor le recuerda su estar-ahí en el mundo, su corporeidad, diametralmente opuesta a la de los fantasmas que visitará.

La sensorialidad no solo se relaciona con la dimensión real y física que el narrador busca transmitir, sino que guarda también un paralelismo con la dimensión onírica, pues es sabido que muchas veces el soñador suda al hallarse en medio de una pesadilla: rasgo sensorial que traza un puente entre el sueño, lo ilusorio, y lo real, físico. Por otra parte, cabe recordar la dimensión emocional que guarda el sentido háptico. El protagonista de Réquiem padece de herpes zóster, enfermedad recurrente en la novelística de Tabucchi. Esta 
funciona como metáfora del remordimiento, de lo no dicho, aquello que permanece dormido, pero que "explota" hacia el exterior de manera violenta y dolorosa.

En cuanto al sentido de la vista, el narrador describe Lisboa con algunas notas de colores vivos, capaces de connotar un significado imperceptible a simple vista. Tuan advierte sobre las variaciones en la valoración del simbolismo de los colores, pero admite que en casi todas las culturas hay ciertas coincidencias con respecto a algunas tonalidades. Por ejemplo, el rojo, el naranja y el amarillo casi universalmente son estimados como colores que "avanzan", que tienen peso, en oposición al verde y el azul, que parecen "retroceder" y remitir a una idea de liviandad. Algo similar sucede con el blanco y el negro: "Ambos colores simbolizan principios universales opuestos aunque complementarios. Pares análogos son: luz-oscuridad, aparición-desaparición, vida-muerte. En realidad, estas antinomias son formas diferentes de referirse a lo mismo. Son las mitades necesarias de una realidad total" (Tuan, 2007: 43).

El episodio de Réquiem del cual podemos extraer la mayor cantidad de imágenes cromáticas es el momento en que el protagonista, dirigiéndose hacia el cementerio donde yacen los restos de su amigo Tadeus, compra unas camisetas a un grupo de gitanas para cambiar su camisa excesivamente sudada. Aparece un personaje, la Vieja Gitana "vestida de negro, con un pañuelo amarillo en la cabeza" (Tabucchi, 1991: 28). Según Chevalier (1986), el negro "se sitúa sobre el eje norte-sur, que es el de la trascendencia absoluta y de los polos" (747). La Gitana es una clave que anuncia que el narrador entenderá el sentido profundo de su viaje y podrá acceder, desde su sueño, a una nueva dimensión en la que hablará con los fantasmas que lo visitarán. Continuando con este cambio de eje, el amarillo es en muchas culturas un color que conecta con lo divino. La mujer le vende al narrador una camisa azul, color elegido por ella, por considerarlo el más apropiado para él. Este color es el más inmaterial del círculo cromático, y siempre tiene connotaciones espirituales; en diversas culturas es el más asociado con el cielo (Chevalier, 1986: 163166). El encuentro con la gitana recuerda al lector que el viaje del protagonista tiene una dimensión espiritual: en la lectura de la palma de la mano, la Vieja 
Gitana le explica y anuncia: "no puedes escapar a tu destino, va a ser un día de tribulaciones, pero también de purificación, tal vez después quedes en paz contigo mismo" (Tabucchi, 1991: 28). Este viaje a Lisboa es, precisamente, la oportunidad de encontrarse con seres del pasado, y el protagonista viste durante su itinerario su nueva camisa azul, como si se tratase de una suerte de talismán que facilita el acceso a ese más allá donde se darán las entrevistas con los muertos.

Inmediatamente después de la lectura de la mano, se da el primer contacto con un "fantasma", que ocurre en el Cementerio dos Prazeres. Se trata de Tadeus, el amigo fallecido del narrador. El cementerio es un umbral que conduce al protagonista a un nuevo mundo, a otra dimensión: aquella en la que se puede hablar con los muertos, y en la que se entrecruzan el presente y el pasado. El narrador se enfrenta a la lápida de su amigo y casi imperceptiblemente se transporta a la antigua casa de Tadeus, quien lo invita a almorzar en un restaurant para probar un plato de sarrabulho, cuyo aspecto le genera las siguientes impresiones:

A simple vista, tenía un aspecto repugnante. En el centro de la bandeja estaban las patatas, doradas por la grasa, y alrededor, los trozos de carne y las tripas. El conjunto estaba empapado por una salsa marrón que debía ser de vino o de sangre cocida, no tenía la más mínima idea. (Tabucchi, 1991: 41)

El episodio gastronómico reúne dos aspectos que se entrecruzan en toda la novela. Por un lado, están la corporalidad y la muerte, sugeridas por la isotopía que conforman "carne", "tripas" y "sangre" en el fragmento citado. Por el otro, se despliegan la espiritualidad y la vitalidad que proporciona la acción del comer. El autor es consciente de que la alimentación es una afirmación de la vida frente a la muerte, a la que se desea desafiar; es por eso que los ritos fúnebres están unidos a rituales alimenticios. Como dice el propio Tadeus, "el alma se cura con la barriga" (Tabucchi, 1991: 49).

Curar el alma es una de las misiones del protagonista durante su estadía en Lisboa. En los encuentros con los fantasmas él busca apaciguar 
remordimientos persistentes en su vida lúcida, y en la entrevista con Tadeus se despliegan interrogantes que necesita despejar. Durante la conversación surgen recuerdos, una sensación de nostalgia, y también tensiones y resquemores. De hecho, en el momento más tenso del diálogo entre los viejos amigos, el dueño del restaurant les acerca un postre dulce, los papos de anjo ${ }^{3}$ (papadas de ángel), que contrarresta la amargura que el tono de la visita había tomado.

Los platos servidos en este episodio (y en muchos otros que por cuestiones de espacio no es posible abordar aquí) resultan una nota de antropología cultural, característica en la prosa de Tabucchi, quien se vale del recurso de lo gustativo para imprimir en el texto un sentido de identidad y de nostalgia por el pasado. El autor, en entrevistas recopiladas por su traductor al español, Carlos Gumpert (1995), comenta que algunas recetas incluidas en este libro pertenecen a platos casi olvidados en la actualidad, por lo que se podría reconstruir esta Lisboa del pasado mediante sus platos y bebidas.

Dicha reconstrucción no solo nos hablaría a secas de la dieta de los portugueses; a lo largo del texto, Tabucchi saca provecho de que su protagonista sea italiano, pues da lugar al choque cultural entre él y los demás personajes, quienes, en su calidad de portugueses, se reflejan a sí mismos en este otro extranjero para constituir una identidad, un "nosotros" frente a un "ustedes" o un "ellos" más lejano. Precisamente, otro episodio gastronómico sirve de ejemplo. Se trata de la visita al Museo de Arte Antiguo, en cuyo bar el protagonista pide un Sumol, una "bebida gaseosa aromatizada, muy azucarada" (Tabucchi, 1994: 139) para hacer la digestión tras el pesado sarrabulho. Al no ser un trago alcohólico, despierta en el Barman la protesta de estar malgastando su profesión en servir bebidas suaves. Según él, estas son las preferidas por la mayoría de los consumidores locales, quienes no comprenden nada sobre el buen beber, ya que "en este país la gente no sabe nada" a diferencia de bebedores como los franceses o los ingleses, "gente que bebe de verdad, no como los portugueses, que sólo beben naranjadas"

3 "Era un plato de dulces amarillos en forma de barquitos. Son papos de anjo de Mirandela, dijo el Señor Casimiro con orgullo, yemas de huevo y dulce de frutas" (Tabucchi, 1994: 47). 
(Tabucchi, 1994: 67-68).

El olfato es uno de los sentidos que más fuertemente transporta por los senderos del recuerdo. Algo así le sucede al protagonista, quien, al volver a una casa de las afueras de Lisboa en la que pasaba los veranos, describe: "Entramos y reconocí de inmediato el olor de la casa. Era un olor vagamente parecido al del metro de París en invierno, a medio camino entre el moho, el barniz y la caoba, un olor que solo aquella casa tenía, y que ahora me volvía a la memoria" (Tabucchi, 1991: 93).

El olor es lo primero que el personaje siente al entrar en ella, es el disparador de todos los otros recuerdos y sensaciones que emergerán de esa visita. La decrepitud de la antigua casa está en consonancia con los rastros del paso del tiempo que la ciudad sufre en muchos aspectos; es más, la casa tiene dueños extranjeros, que esperan que se derrumbe para construir en su lugar un hotel lucrativo. En una sintonía similar, el narrador y los demás personajes notan que la Lisboa que ellos conocen está en constante cambio: "los gustos han cambiado ahora en todo" (Tabucchi, 1991: 86), "este país está en venta” (Tabucchi, 1991: 90), “este país está volviéndose terriblemente europeo" (Tabucchi, 1991: 125). De esta manera, en todo Réquiem se percibe el contraste entre el pasado de la ciudad — vívido en la nostalgia y el recuerdo de quienes la habitan — y su presente, cambiante e insatisfactorio. Podríamos resumir las sensaciones de los personajes con la palabra portuguesa saudade, "categoría ubicada a mitad de camino entre la añoranza y la melancolía, una nostalgia sin causa, en estado puro" (Capano, 2007: 74). En una entrevista, Tabucchi explica que, para él, la saudade es "una nostalgia del pasado, pero también una nostalgia del futuro, de lo que quisiéramos ser y no somos, de lo que habríamos podido ser y no hemos sido" (apud Capano, 2007: 75).

Hacia el final del viaje y a medianoche, tras compartir una cena, el fantasma de Fernando Pessoa y el narrador se encuentran con el Tocador de Acordeón, un artista callejero que ofrece deleitarlos con su música. El protagonista y el fantasma le piden fados antiguos, más que los tradicionales. Pessoa le pide "Sâo tâo lindos os teus olhos", y mientras el artista toca la pieza, el fantasma asocia recuerdos de su juventud con ese fado y los tres se 
dirigen hacia el muelle donde empezó el viaje del narrador. La audición es un sentido que delata mucho más la vulnerabilidad del sujeto. Explica Tuan (2007) que “«Oír» tiene una connotación de pasividad (receptividad) que «ver» no posee" (20). Es precisamente la música un elemento que despierta la emoción de quien la escucha, y no es inocente la elección del fado como la variedad musical presente en la novela. La conexión entre la percepción de la música y la irrupción de emociones y recuerdos del oyente se debe a que, debido a sus orígenes marítimos, "fado è desiderio e lamento insieme, un sentimento associato all'idea di destino (dal latino fatum), quintessenza della saudade" (Pini, 2018: 116).

\section{COSMOVISIÓN: LA CIUDAD DE LA NOSTALGIA}

A medida que recorre la ciudad y sus sentidos aprehenden cada detalle de ella, el protagonista se ve en condiciones de tener una visión global de lo que, en su experiencia, es la ciudad de Lisboa. A su vivencia se unen las voces de los personajes visitados, cada uno con su opinión sobre el espacio habitado. Ya se ha señalado que la ciudad de Lisboa se presenta de manera fragmentaria; de la misma manera, resulta que las distintas miradas que la reconstruyen también son de carácter parcial.

Al estudiar la percepción de la ciudad por parte de sus habitantes, Néstor García Canclini explica que estos no son capaces de representarse a sí mismos la ciudad en su totalidad, pues los humanos "organizamos selectivamente nuestra experiencia del entorno urbano" (2003: 14). En cambio, a los habitantes les es posible imaginar la ciudad donde viven a partir de los "pequeños entornos a su alcance", es decir, de los itinerarios recorridos y espacios ocupados día a día (2003: 9-10). A la representación del espacio urbano habitado por los ciudadanos, este teórico la llama "imaginario urbano", concepto que resulta cercano al de "cosmovisión" postulado por Tuan.

Si bien no se explicita en qué fecha exacta se sitúa la acción de Réquiem, es dable pensar que se desarrolla alrededor de los años ochenta, época de 
apertura del país a la Unión Europea y a la globalización, resistida hasta entonces. De ahí la sensación de pérdida de muchos de los interlocutores del protagonista, nostálgicos por el pasado y renuentes a que el país mire cada vez más a Europa y menos al océano, a que las costumbres y gustos se acerquen más a los continentales. Surge también la comparación, a veces más benévola para el extranjero que para el local. La novela va creando paulatinamente una imagen de lo que es ser portugués y habitar una ciudad que cambiará inexorablemente en la medida en que cambie la mirada de los que la visitan y viven en ella.

Al evocar una ciudad onírica y ya desaparecida, es decir, "imaginaria", el narrador de Tabucchi configura una auténtica ciudad de la nostalgia. Como Clément Colin, este sentimiento puede constituirse como una "herramienta de apropiación del espacio" (2017: 94). Esto sucede en la medida en que "la nostalgia permite comprender comportamientos y discursos que se vinculan con ideas y valores inscritos en un tipo de relación subjetiva con el espacio y el tiempo", de modo que a través de ella "se cuestionarán las dimensiones subjetivas y afectivas del cambio urbano" (2017: 101). En la obra de ficción analizada, en efecto, la nostalgia no solo se siente, sino que además se ejerce mediante la rememoración de hábitos o valores pasados.

Al respecto resulta significativo el episodio gastronómico al final de Réquiem, en el cual el narrador comparte una velada con el fantasma de Pessoa en un restaurant. Se trata de un local "posmoderno", donde se ofrecen platos poco interesantes con nombres extravagantes ${ }^{4}$ muy distintos a los que el narrador presentó en páginas anteriores, ligados a tradiciones ya casi olvidadas. El fantasma es capaz de comparar la Lisboa que él vivió con la que está visitando. Para aquella capital Europa era "algo remoto, lejano, era un sueño" (Tabucchi, 1994: 131), a diferencia de lo que sucede en la ciudad actual, que se acerca cada vez más al resto del continente. De ese modo, el fantasma del

4 El camarero presenta los platos: "la sopita Amor de perdición es una sopa de cilantro con mucho cilantro y menudillos de gallina". Los comensales más tarde concluyen que "no eran más que dos sopas de cilantro a la manera tradicional" (Tabucchi, 1994: 127-130). 
poeta portugués se convierte, como otros personajes ya mencionados, en una figura de "autoridad", poseedor de los recuerdos que parecían emparentarse con cierta identidad en peligro del pueblo portugués.

Mientras que la ciudad de Lisboa de las últimas décadas del siglo XX se hallaba en un proceso de modernización y apretura, con miras hacia el futuro, ${ }^{5}$ la ciudad soñada por el protagonista revela el deseo de recuperar y habitar el pasado. El propio título de la novela refleja esa tensión entre la ciudad (soñada) del pasado y la ciudad (plausiblemente real) del futuro. En el prólogo a la nouvelle, donde Tabucchi explica su deseo de homenajear la ciudad, aclara que su réquiem carece de la solemnidad del latín y del órgano y que, al estar escrito en portugués, se fusiona con su gusto personal por lo tradicional y popular. Su réquiem no solo será una "oración de difuntos" dedicada a las almas de los personajes de la novela; será también una sonata para la Lisboa que, a causa del paso del tiempo y de los cambios que este trae consigo, no será nunca igual. Réquiem es un intento de "congelar" el tiempo, de mostrar cómo ha sido y cómo sus personajes (y por qué no, su autor) quieren que continúe siendo Lisboa, en una actitud (siguiendo a Tuan) de nostalgia por el pasado y el futuro, corporeizando un ánimo de saudade.

\section{CONCLUSIÓN}

Hemos recorrido la nouvelle de Tabucchi haciendo foco en algunos episodios donde los cinco sentidos determinan la percepción espacial del protagonista. Creemos que esta forma de experimentar la ciudad, que pone en segundo plano la racionalidad y el intelectualismo que puedan surgir de análisis

5 El geógrafo italiano Lorenzo Pini explica que en 1986, año que podríamos presumir dentro del contexto de génesis de la novela, "[a]rrivano i finanziamenti legati all'ingresso nell'Unione Europea del Portogallo. Le rive del Tago divengono oggetto di piani di riconversione industriale e investimento immobiliare. Ma soprattutto si edifica seguendo i canoni di un architettura appariscente" (Pini, 2018: 144-145). La ciudad portuaria se abre a nuevas actividades económicas y una fisonomía innovadora, sin que esta se adecuara necesariamente a la tradicional. 
posteriores, revela al lector que el del narrador es un trabajo de aprehensión del espacio en extremo personal e íntimo. Este aspecto permite inscribir la novela en el contexto de la llamada literatura posmoderna, en la que "el espacio se ha vuelto subjetivo, no existe más que a través de la percepción que el individuo tiene de él" (Tudoras, 2006: 130). En el texto analizado, los sentidos perciben el espacio exterior basándose en valoraciones previamente establecidas, que se reelaboran en el individuo de una manera sumamente original para crear una imagen de la ciudad y de la identidad de sus habitantes.

Asimismo, hemos comprobado que, para el protagonista, Lisboa es el lugar en que se entrecruzan el presente y el pasado. El primero genera una sensación de insatisfacción y de pérdida de ese pasado que fue mejor, donde todo era más simple y más bello. Revivir y comunicar el pasado funcionan como estrategias de los personajes para ejercer una apropiación del espacio urbano. Ellos apelan a un pasado que no permanece inmutable, sino que vuelve para que el narrador pueda solucionar culpas y remordimientos guardados en el fondo de su alma. Como los mismos fantasmas, el herpes zóster retorna en tanto síntoma para enseñarle — en la piel— que hay heridas profundas que aún no ha sanado. Las visitas de los fantasmas y la enfermedad no solo corporizan el cruce entre pasado y presente; reflejan además la tensión entre la muerte y la vida que se resignifican mutuamente: el vivo necesita respuestas y consuelo, pero así también algunos muertos, como el padre del protagonista, que se le aparece en un sueño dentro de este gran sueño lisboeta, necesitan resolver ciertos interrogantes para poder descansar en paz.

En la obra analizada, Tabucchi se interroga, además, acerca de la vida y la muerte del concepto de alma. Al inicio de la alucinación, el protagonista se encuentra con un personaje que le comenta: "Estoy leyendo un artículo de un filósofo francés sobre el alma [...], durante mucho tiempo nadie ha hablado de ella" (1991: 17). Al preguntarle al narrador si él cree que el alma existe, este responde afirmativamente: "ha sido mi alma la que me ha proporcionado todo esto, mejor dicho, no sé si es mi alma, tal vez sea el Inconsciente, porque ha sido mi inconsciente el que me ha traído hasta aquí” (Tabucchi, 1991: 17). Luego sigue una breve discusión acerca de la predominancia de estos conceptos en 
la mentalidad mediterránea: “¿qué quiere decir eso de Inconsciente? [...] aquí estamos en Portugal y el señor es italiano, nosotros pertenecemos al Sur, a la civilización grecorromana, nada tenemos que ver con Centroeuropa, perdone, nosotros tenemos alma" (Tabucchi, 1994: 18).

Esta disputa psijé-alma versus psiquis-inconsciente refleja, por un lado, la percepción del local en su propia cultura, y por otro, el quiebre en la percepción que el hombre tiene de sí mismo. En este sentido, el inconsciente hereda del antiguo concepto de alma el hecho de resultar misterioso, vago y difícil de desentrañar, como un doble oculto que de vez en cuando aflora. Parecería que en el mundo en que transcurre Réquiem, la conciencia se ha separado del alma e impera sobre ella; entonces el sujeto se percibe mutilado y fragmentado, tanto como la ciudad que lo rodea.

Los lugares elegidos de Lisboa y la experiencia del protagonista al percibirlos la vuelven una ciudad atemporal, que trasciende el pasado y el incierto futuro, una ciudad que es más que el lugar donde se habita o se pasea: es la ciudad de los sueños, la nostalgia y el alma escondida, donde se recoge el pasado para sanar dudas y vacíos del presente, donde se puede invocar a la muerte para reafirmar y prolongar la vida misma.

\section{REFERENCIAS}

Capano, Daniel Alejandro. El errático juego de la imaginación. La poética de Antonio Tabucchi, Buenos Aires: Biblos, 2007.

Chevalier, Jean. Diccionario de los símbolos. Barcelona: Herder, 1986.

Colin, Clément. "La nostalgia en la producción urbana: la defensa de barrios en Santiago de Chile ”, Revista Invi 32/91 (2017): 91-111.

García Canclini, Néstor. "México 2010: una ciudad que improvisa su globalización", Alteridades 13/26 (2003): 7-14.

Gumpert, Carlos. Conversaciones con Antonio Tabucchi. Barcelona: Anagrama, 1995.

Freud, Sigmund. Obras completas IV. La interpretación de los sueños (primera parte). Buenos Aires: Amorrurtu editores, 1991. 
Tabucchi, Antonio. Réquiem. Una alucinación. Barcelona: Anagrama, 1994. Tuan, Yi-Fu. Topofilia. Santa Cruz de Tenerife: Melusina, 2007.

Tudoras, Laura Eugenia. "Propuesta para una lectura postmoderna de la ciudad”, Cuadernos de Filología Italiana 13 (2006): 129-141.

Pini, Lorenzo. A Lisbona con Antonio Tabucchi. Una guida. Roma: Giulio Perrone Editore, 2018.

Westphal, Bertrand. "Aportes para un enfoque geocrítico de los textos". Espacios, imágenes y vectores. Desafios actuales de las literaturas comparadas. García, M., M. J. Punte y M. L. Puppo (comps.). Buenos Aires: Miño y Dávila, 2015: 27-57. 